\title{
KAJIAN SEMIOTIKA TIPOLOGI TANDA PADA TEPAK SIRIH DAN BALE DI MEDAN DELI
}

\author{
Tiara Chairunnisa \\ Fakultas Bahasa Dan Seni \\ Universitas Negeri Medan \\ E-mail : tiarachairunnisa82@gmail.com
}

\begin{abstract}
Abstrak
Penelitian ini bertujuan untuk mengetahui bagaimana pemahaman terhadap Tepak Sirih dan Bale Melayu dikaji berdasarkan aspek representamen, hubungan representamen dengan objek, dan interpretan. Metode yang digunakan adalah metode kualitatif deskriptif, dengan penerapan teori semiotika Charles Sanders Peirce, untuk memberikan gambaran secara jelas mengenai pemaknaan tipologi tanda yang terdapat pada tepak sirih dan bale Melayu di Kecamatan Medan Deli. Hasil penelitian menjelaskan bahwa kehadiran tepak sirih dan bale Melayu merupakan suatu representamen atau tanda yang bersifat indrawi. Dalam hubungan representamen dengan objek, kehadiran tepak sirih dan bale Melayu mengacu pada suatu bentuk atau wadah untuk menempatkan sesuatu, yaitu sirih dan perencahnya (tepak) serta nasi dan lauk pauk (bale Melayu). Berdasarkan interpretan, pemahaman terhadap tepak sirih dan bale Melayu merupakan tanda lain yang ekuivalen, yaitu sebagai adat istiadat atau budaya Melayu.

kata kunci: Semiotika; Charles Sanders Peirce; tepak sirih; bale Melayu.
\end{abstract}

\begin{abstract}
This study aims to determine how the understanding of Tepak Sirih and Bale Melayu is assessed based on the symbolic aspects, the relationship between the representamen and the object, and the interpretant. The method used is a descriptive qualitative method, applying Charles Sanders Peirce's semiotic theory to provide a clear description of the meaning of the typology of signs found in tepak sirih and bale Melayu in Medan Deli District. The study results explain that the presence of tepak sirih and Malay bale is a sensory representation or sign. In relation to representation and object, the company of tepak sirih and bale Melayu refers to a form or container to place something, namely betel and its perencah (tepak) and rice side dishes (malay bale). Based on the interpretation, the understanding of the tepak sirih and the Malay bale is another equivalent sign, namely as a Malay custom or culture. keywords: Semiotics; Charles Sanders Peirce; betel palm; Malay bale.
\end{abstract}

\section{PENDAHULUAN}

Kota Medan dikenal sebagai kota kesultanan Melayu Deli. Oleh sebab itu, dalam perkembangan kotanya hingga sekarang berupaya mempertahankan identitas Melayu, walaupun kehidupan masyarakatnya yang sangat beraneka ragam, dikarenakan statusnya sebagai ibu kota provinsi Sumatra Utara (Zulkifli et al., 2021) Identitas Melayu diantaranya ialah tepak sirih dan bale Melayu.
Tepak sirih dan bale Melayu dari zaman dahulu hingga sekarang sudah mengalami perubahan. Berdasarkan hasil observasi dan wawancara yang dilakukan oleh peneliti dengan Tokoh Adat Melayu Sumatra Utara dan sebagai Ketua Himpunan telangkai lestari adat Melayu Sumatra Utara yaitu Bapak Hidayat Alamsyah di Sanggar Rangkain Deli pada hari Kamis 05 November 2020. Beliau mengatakan "zaman dulu tepak ni satu 
warna dia, warna coklat dari kayu diukir dan dipernis warna coklat, sekarang zaman sudah canggih tepak tadi di bungkus kain songket, kain songket bermacam-macam berwarna-warna". Pernyataan inimembuktikan bahwa tepak sirih mengalami perubahan dari zaman dahulu yang berwarna coklat tidak berbungkus kain songket dan zaman sekarang yang berbungkus kain songket berwarna warni. Beliau juga mengatakan "kalau zaman duluyang dipakai cuman 2 warna bale, satu warna putih untuk orang hatam kaji dan naik haji, kalua acara resepsi pernikahan warnannya kuning. Jadi sekarang tidak, sekarang dibuat orang warna ungu,merah, coklat berbagai macam warna supaya terlihat cantik". Pernyataan ini membuktikan bahwa bale juga mengalami perubahan dari segi warna yang di zaman sekarang menggunakan beragam warna, padahal warna yang digunakan suku Melayu hanya warna kuning dan hijau. Unsur warna dalam tradisi melayu adalah kuning, kemudian hijau dari pengaruh islam (Zulkifli et al., 2021).

Berdasarkan pengamatan peneliti terhadap tepak sirih dan bale Melayu banyak orang yang tidak memahami tanda-tanda yang terdapat pada tepak sirih dan bale Melayu, karena tidak mempelajari semiotika dan masih jarang ada yang menjelaskan berdasarkan tipologi tanda menurut Charles Sanders Peirce pada aspek representamen, hubungan representamen dengan objek, dan interperetan. Sehingga banyak orang yang kurang paham tentang makna tepak sirih dan bale Melayu ditinjau dari semiotika. Hal ini pula yang membuat penulis merasa perlu untuk membahas kajian tentang semiotika. Semiotika adalah suatu pendekatan teoritis yang sekaligus berorientasi terhadap kode dan pesan tanpa mengabaikan konteks dan pihak pembaca.

Pembahasan terkait semiotika ini sebelumnya telah dipaparkan pada penalitian Salleh (2014) dengan judul "tepak sirih interpretasi dan persepsi dalam masyarakat Malaysia-Indonesia”. Pada penelitian ini membahas peranan tepak sirih sebagai alat komunikasi bukan lisan dalam masyarakat Malaysia- Indonesia dengan menggunakan teori Charles Sanders Peirce. Maka dapat disimpulkan bahwa semiotika dapat memahami berbagai makna yang terdapatpada produk budaya.

Selanjutnya penelitian Mubarat (2016) yang bejudul "kajian bentuk dan fungsi seni kerajinan leuker tepak sirih Palembang”. Penelitian ini membahas bentuk dan fungsi dari seni kerajinan leuker tepak sirih Palembang. Hasil dari penelitian ini tepak sirih tersebut memliki bentuk dan fungsi yang bernilai sejarah, sosial, budaya serta fungsi estetik yang terorganisasi menjadi satu kesatuan menjadi karya seni yang bernilai klasik.

Berikutnya penelitian Sudiani (2016) dengan judul "analisis desain uang kertas pecahan seratus ribu rupiah". Pada peneltian ini membahas makna makna simbolik yang ada dalam uang seratus ribu rupiah. Maka dapat disimpulkan bahwa makna yang terdapat dalam uang seratus ribu rupiah yaitu makna persatuan dan kesatuan dalam proklamasi. Menurut Sugiono (2017) metode penelitian merupakan cara ilmiah untuk mendapatkan data atau informasi sebagaimana adanya dan bukan sebagaimana seharusnya, dengan tujuan dan kegunaan tertentu penelitian ini menggunakan metode penelitian kualitatif deskriptif. Hal ini berdasarkan pada 
karakteristik

penelitian

yang dikemukakan oleh Yusuf (2014) bahwa:

"Penelitian kualitatif merupakan suatu strategi inquiri yang menekankan pencarian makna, pengertian, konsep, karakteristik, gejala, simbol maupun deskripsi tentang suatu fenomena; mengutamakan kualitas, menggunakan beberapa cara, serta disajikan secara naratif".

Sesuai dengan objek kajian penelitian ini dalam upaya menafsirkan makna tipologi tanda aspek representamen, hubungan representamen dengan objek dan interpretan dari tepak sirih dan bale Melayu, penelitian ini menggunakan pendekatan deskriptif kualitatif, dimana peneliti berupaya mentafsirkan tepak sirih dan bale Melayu dengan penerapan teori semiotika Charles Sanders Peirce untuk memberikan gambaran secara jelas mengeanai makna tipologi tanda aspek representamen, hubungan representamen dengan objek dan interpretan dari tepak sirih dan bale Melayu. Hasil dari pengklasifikasian tersebut kemudian dianalisis dengan model semiotic Chaeles Sanders Peirce yaitu dengan cara mencari makna aspek representamen, hubunagn representamen dengan objek dan interpretan dalam masing masing tepak sirih dan bale Melayu.

Indikator masing-masing seperti yang tertulis dalam Budiman (2011) adalah: 1) representamen, Sesuatu yang bersifat indrawi atau material yang berfungsi sebagai tanda. Kehadirannya menimbulkan interpretan, yakni tanda lain yang ekuivalen dengannya; 2) hubungan representamen dengan objek, apa saja yang dianggap ada, tidak hanya yang kasat mata, juga yang abstrak, imajiner, fiktif, dll; 3) interpretan, Kehadiran membangkitkan interpretan, yaitu tanda yang ekuivalen didalam benak seseorang. sesuatu yang lain itu dinamakan interpretan.

Setelah dibahas dengan singkat mengenai semiotika Charles Sanders Peirce, kemudian tepak sirih dan bale Melayu atau data penelitian diolah dengan cara mengamati berbagai tanda yang terlihat langsung berdasarkan visualisasi pada tepak sirih dan bale Melayu untuk menemukan makana relasi tanda aspek representamen sebagai pemaknaan tingkat pertama. Kemudian mengungkapkan makna relasi tanda hubungan representamen dengan objek. Setelah itu akan ditemukan makna relasi tanda aspek interpretan terhadap tepak sirih dan bale Melayu.

\section{HASIL DAN PEMBAHASAN}

Charles Sanders Peirce adalah seorang filsuf Amerika, ahli matematika dan penemu pragmatisme yang hidup diperalihan pada abad (1839-1914) yang lalu. Sebagai seorang filsuf dan ahli logika, Peirce berkeinginan untuk menyelidiki apa dan bagaimana proses bernalar manusia. Teori Peirce tentang tanda dilandasi oleh tujuan besar ini sehingga tidak mengherankan jika dia menyimpulkan bahwa semiotika tidak lain dan tidak bukan adalah sinonim bagi logika (Budiman, 2011). Teori yang dikemukakan oleh Charles sanders Peirce yaitu semiotika tipologi tanda berdasarkan aspek Representamen, hubungan Representamen dengan Objek dan Interpretan.

Peirce (dalam Budiman, 2011) 


\section{MELAYUARTS AND JOURNAL}

mengatakan:

"A sign, or representamen, is something which stands to somebody fir something is some respec or capacity. It adresses somebody, that is, creates in the mind of that person an equivalent sign, or perhaps a more developed sign. That sign which it creates I call the interpretant of the first sign. The sign stands for something, its object. It stands for that ibject. Not in all respects, but in reference to a sort of idea, which I have sometimes called the ground of the representamen".

"suatu tanda, atau representamen, merupakan suatu yang menggantikan sesuatu bagi seseorang dalam beberapa hal atu kapasitas. Ia tertuju kepada seseorang, artinya didalam benak orang itu tercipta suatu tanda lain yang ekuivalen, atau mungkin suatu tanda yang lebih berkembang. Tanda yang tercipta itu saya sebut sebagai interpretan dari tanda yang pertama. Tanda menggantikan sesuatu, yaitu objeknya, tidak dalam segala hal, melainkan dalam rujukannyapada sejumput gagasan, yang kadang saya sebut sebagai latar dari reresentamen”.

Reresentamen adalah sesuatu yang bersifat indrawi atau material yang berfungsi sebagai tanda. Peirce membedakan representamen menjadi qualisign, sinsign dan legisgn. Kulitas tanda yang disebut dengan qualisign, sinsign adalah eksistensi tanda terhadap peristiwa yang dialami dan legisign adalah eksistensi tanda dengan konsep dan aturan yang berlaku umum (Patriansyah, 2014).

Objek yang diacu tanda adalah realitas, apa saja yang dianggap ada, tidak hanya yang kasat mata, juga yang abstrak, imajiner, fiktif, dan lainnya. Peirce mengatakan bahwa dalam teori semiotika

\section{Vol. 4, No. 1, April, 2021}

walaupun simbol atau lambang merupakan kategori tanda (sign), dan ia menyatakan bahwa tanda (sign) terdiri atas ikon, indeks dan symbol dan tanda adalah 2 hal yang berbeda (Sobur, 2004).

“.......tanda sebagai Representamen dan konsep, benda, gagasan, dan seterusnya, yang diacunya sebagai Objek. Makna (impresi, kogitasi, perasaan, dan seterusnya) yang kita peroleh dari sebuah tanda oleh Peirce diberi istilah Interpretan (Marcel Danesi, 2010).

Setiap tanda yang dipahami oleh seseorang membangunkan atau berasosiasi dengan tanda lain di dalam benaknya. Tanda yang kemudian ini merupakan interpretan dari yang pertama. Misalnya, selembar gambar pisang menyebabkan munculnya kata pisang sebagai interpretan didalam benak seseorang (Budiman, 2011).

Semiotika merupakan ilmu yang mempelajari tentang tanda, semiotika adalah sebuah alat yang dapat digunakan untuk menganalisa sebuah karya (Ramadhan, n.d.)

Charles Sander Peirce menciptakan skema yang akhirnya menjelelaskan bagaimana tanda bekerja, sebagai berikut:

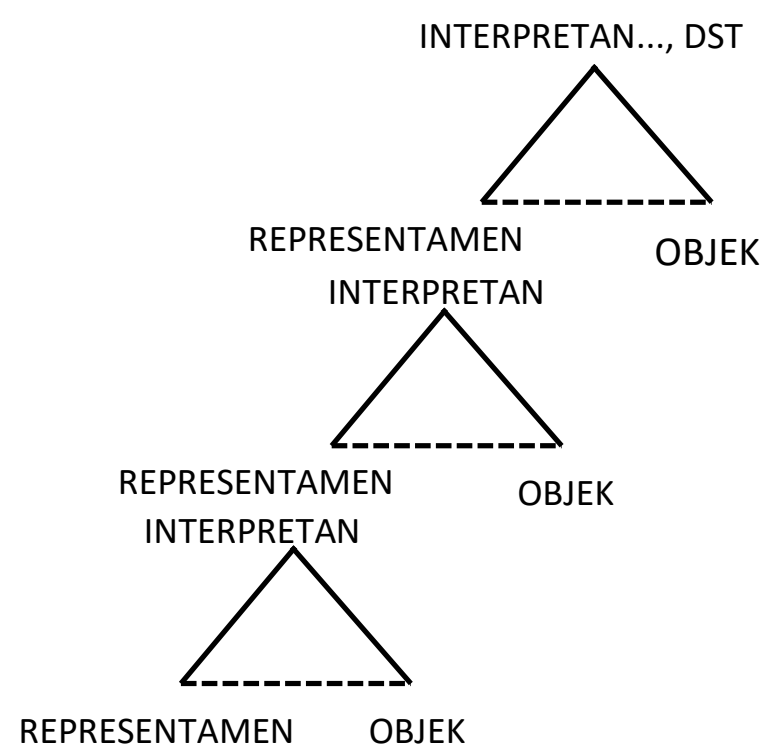

Gambar 1: Skema Proses Semiosis Sumber: Budiman (2011) 
Penjelasan dari skema diatas yaitu, sebuah tanda atau representamen adalah sesuatu yang mewakili sesuatu yang lain dalam beberapa hal atau kapasitas. Ia merupakan segala sesuatu yang menentukan sesuatu yang lain (disebut interpretant) agar mengacu pada sebuah objek. Maka pada gilirannya sebuah interpretan akan menjadi representamen, menjadi interpretan lagi, menjadi representamen lagi dan seterusnya (Budiman, 2011). Misalnya, jika gambar telepon pada rambu lalu lintas adalah sebuah representamen, menjadi interpretan lagi, menjadi representamen lagi dan seterusnya (Budiman, 2011). Misalnya, jika gambar telepon pada rambu lalu lintas adalah sebuah representamen, maka interpretannya adalah telepon, kata telepon ini pun pada gilirannya akan berkedudukan sebagai sebuah representamen dan alat komunikasi jarak jauh, dengan rujukan pada objek tertentu pula, dan seterusnya dan sterusnya, sambung sinambung tanpa pernah selesai.

Pada pembahasan ini dipaparkan data dari hasil penelitian yang dilakukan pada tepak sirih dan bale Melayu di Kecamatan Mean Deli. Paparan data ini djelaskan berdasarkan objek kajian beserta isinya untuk menjawab rumusan masalah dan tujuan penelitian. Pendekatan yang dilakukan berdasarkan semiotika Charles Sanders Peirce dengan mencermati relasi tanda dan aspek pemaknaan representamen, hubungan representamen dengan objek, dan interpretan. Paparan datanya meliputi empat sampel yaitu tepak sirih berwarna coklat, tepak sirih berwarna hijau, bale Melayu berwarna putih, dan bale Melayu berwarna kuning. Kemudian isi tepak sirih berupa sirih, kapur, pinang, tembakau, dan gambir sebagai berikut:

\section{Tabel Hasil Identifikasi Objek Penelitian \\ Berdasarkan Aspek Representamen}

\begin{tabular}{|c|c|}
\hline No. & \multicolumn{1}{|c|}{ Gambar } \\
\hline 1 & Tepak Sirih Berwarna Coklat \\
& - Representamen: Tepak Sirih \\
& Qualisign: Mengesankan \\
& ketegasan, kesederhanaan \\
& $\begin{array}{l}\text { Sinsign: Ketegasan terdapat } \\
\text { pada bentuknya yang petak } \\
\text { bersudut, kesederhanaan } \\
\text { terdapat warnanya yang coklat } \\
\text { - Legisign: Secara utuh } \\
\text { memperlihatkan ketegasan } \\
\text { dan kesederhanaan }\end{array}$ \\
\hline 2 & $\begin{array}{l}\text { Tepak sirih Berwarna Hijau } \\
\end{array}$ \\
\hline
\end{tabular}




\begin{tabular}{|l|l|}
\hline - & \\
Representamen: Tepak sirih \\
Qualisugn: Mengesankan \\
ketegasan, kesuburan dan \\
kemakmuran \\
Sinsign: Ketegasan terdapat \\
pada bentuknya yang petak \\
bersudut, kesuburan dan \\
kemakmuran terdapat pada \\
-
\end{tabular}

\begin{tabular}{|c|c|}
\hline & adanya \\
\hline 4 & $\begin{array}{l}\text { - Representamen: Kapur } \\
\text { - Qualisign: Mengesankan } \\
\text { hangat, mengesankan hati } \\
\text { putih bersih } \\
\text { Sinsign: Hangat pada rasa } \\
\text { terdapat pada warnanya yang } \\
\text { putih } \\
\text { Legisign: Secara utuh } \\
\text { memperlihatkan hati yang } \\
\text { putih dan bersih }\end{array}$ \\
\hline 5 & $\begin{array}{l}\text { Pinang Sebagai Isi Tepak Sirih } \\
\text { - Representamen: Pinang } \\
\text { - Qualisign: Mengesankan asam } \\
\text { dan pahit, mengesankan } \\
\text { derajat yang tinggi } \\
\text { - Sinsign: Asam dan pahit pada } \\
\text { rasa pinang, tinggi derajatnya } \\
\text { terdapat pada pohonyna yang } \\
\text { tinggi } \\
\text { Legisign: Secara utuh }\end{array}$ \\
\hline
\end{tabular}


MEl_AYU ARTSAND

Vol. 4, No. 1, April, 2021

JOURNAL

\begin{tabular}{|c|c|}
\hline & $\begin{array}{l}\text { memperlihatkan tinggi } \\
\text { derajatnya }\end{array}$ \\
\hline 6 & $\begin{array}{l}\text { Tembakau Sebagai } \\
\text { Isi Tepak Sirih } \\
\text { - Representamen: Tembakau } \\
\text { - Qualisign: Mengesankan } \\
\text { pahit, mengesankan hati yang } \\
\text { tabah } \\
\text { Sinsign: Pahit pada rasa } \\
\text { tembakau, hati yang tabah } \\
\text { terdapat pada kesan pahit } \\
\text { Legisign: Secara utuh } \\
\text { memperlihatkan hati yang } \\
\text { tabah }\end{array}$ \\
\hline 7 & $\begin{array}{l}\text { - Representamen: Gambir } \\
\text { - Qualisign: Mengesankan kelat, } \\
\text { mengesankan keteguhan hati } \\
\text { - Sinsign: Kelat pada rasa } \\
\text { gambir, keteguhan hati } \\
\text { terdapat pada kesan kelat } \\
\text { Legisign: Secara utuh } \\
\text { memperlihatkan keteguhan } \\
\text { hati }\end{array}$ \\
\hline
\end{tabular}

\begin{tabular}{|c|c|}
\hline 8 & $\begin{array}{l}\text { - Representamen: Bale Melayu } \\
\text { Qualisign: Mengesankan } \\
\text { kesucian } \\
\text { Sinsign: Kesucian terdapat } \\
\text { pada warnanya yang putih } \\
\text { - Legisign: Secara utuh } \\
\text { memperlihatkan kesucian }\end{array}$ \\
\hline 9 & $\begin{array}{l}\text { - Rale Warna Kuning } \\
\text { - Qualisign: Mengesankan } \\
\text { kejayaan } \\
\text { - Sinsign: Kejayaan terdapat } \\
\text { pada warnanya yang kuning } \\
\text { Legisign: Secara utuh } \\
\text { memperlihatkan kejayaan }\end{array}$ \\
\hline
\end{tabular}




\section{Tabel Hasil Identifikasi Objek Penelitian Berdasarkan Aspek Hubungan Representamen dengan Objek}

\begin{tabular}{|c|c|}
\hline No. & Gambar \\
\hline 1 & $\begin{array}{l}\text { Tepak Sirih Berwarna Coklat } \\
\text { - Hubungan Representamen } \\
\text { dengan Objek: Kotak tempat } \\
\text { sesuatu } \\
\text { - Ikon: Bentuk kotak, untuk } \\
\text { tempat sesuatu } \\
\text { - Indeks: Tutup untuk dibuka } \\
\text { dan ditutup, ada kaki agar } \\
\text { mudah diletakkan } \\
\text { - Simbol: Pembuka kata, } \\
\text { pemberian, seserahan, Melayu }\end{array}$ \\
\hline 2 & $\begin{array}{l}\text { - Hubungan Representamen } \\
\text { dengan Objek: Kotak tempat } \\
\text { sesuatu }\end{array}$ \\
\hline
\end{tabular}

- Ikon: Bentuk kotak, untuk tempat sesuatu

- Indeks: Tutup untuk dibuka dan ditutup, ada kaki agar mudah diletakkan

- Simbol: Pembuka kata, pemberian, seserahan, Melayu Sirih Sebagai Isi Tepak Sirih

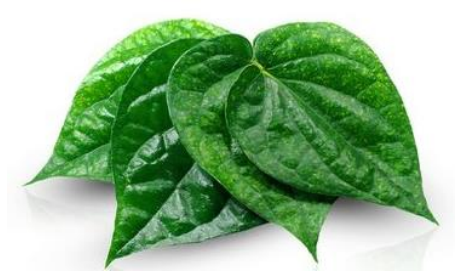

- Hubungan Representamen dengan Objek: Suatu tumbuhan bermanfaat yang tidak merusak tempat sekitarnya tumbuh

- Ikon: Bentuk penyusunan lembaran dedaunan

- Indeks: Tuntutan adat, agar mudah diambil

- Simbol: Rendah diri, senantiasa memuliakan orang lain Kapur Sebagai Isi Tepak Sirih

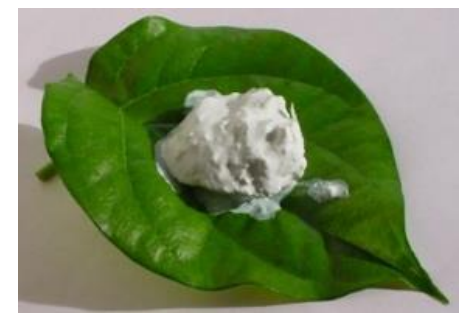

- Hubungan Representamen dengan Objek: Sesuatu yang dapat menjadi putih/bersih 


\begin{tabular}{|c|c|}
\hline & $\begin{array}{l}\text { - Ikon: Bentuk penyajian bahan } \\
\text { - } \text { seperti pasta } \\
\text { Indeks: Suatu tuntutan adat, } \\
\text { mempermudah penggunaan } \\
\text { - Simbol: Hati yang putih } \\
\text { bersih dan tulus }\end{array}$ \\
\hline 5 & $\begin{array}{l}\text { - Hubungan Representamen } \\
\text { dengan Objek: Sesuatu yang } \\
\text { berada diposisi tinggi } \\
\text { - Ikon: bentuk penempatan } \\
\text { ramuan dalam wadah adat } \\
\text { - Indeks: Sesuatu yang menjadi } \\
\text { persyaratan adat, agar mudah } \\
\text { difungsikan dengan bahan } \\
\text { lain } \\
\text { Simbol: Keturunan yang baik } \\
\text { pekerti, tinggi derajatnya, seta } \\
\text { jujur }\end{array}$ \\
\hline 6 & $\begin{array}{l}\text { Tembakau Sebagai Isi Tepak } \\
\text { Sirih } \\
\text { - Hubungan Representamen } \\
\text { dengan Objek: Sesuatu yang } \\
\text { diolah dengan proses }\end{array}$ \\
\hline
\end{tabular}

\begin{tabular}{|c|c|}
\hline & $\begin{array}{l}\text { panjang/lama } \\
\text { - Ikon: bentuk penempatan } \\
\text { ramuan dalam wadah adat } \\
\text { - Indeks: Sesuatu yang menjadi } \\
\text { persyaratan adat } \\
\text { - Simbol: Hati yang tabah dan } \\
\text { bersedia berkorban dalam } \\
\text { segala hal }\end{array}$ \\
\hline 7 & $\begin{array}{l}\text { - Hubungan Representamen } \\
\text { dengan Objek: Sesuatu yang } \\
\text { diperoses untuk mendapatkan } \\
\text { hasil tetentu } \\
\text { - Ikon: Bentuk penyusunan } \\
\text { ramuan dalam wadah adat } \\
\text { - Indeks: Suatu ketentuan adat } \\
\text { - Simbol: Keteguhan hati }\end{array}$ \\
\hline 8 & $\begin{array}{l}\text { Hubungan Representamen } \\
\text { dengan Objek: Wadah untuk } \\
\text { tempat sesuatu } \\
\text { - Ikon: Bentuk wadah untuk }\end{array}$ \\
\hline
\end{tabular}




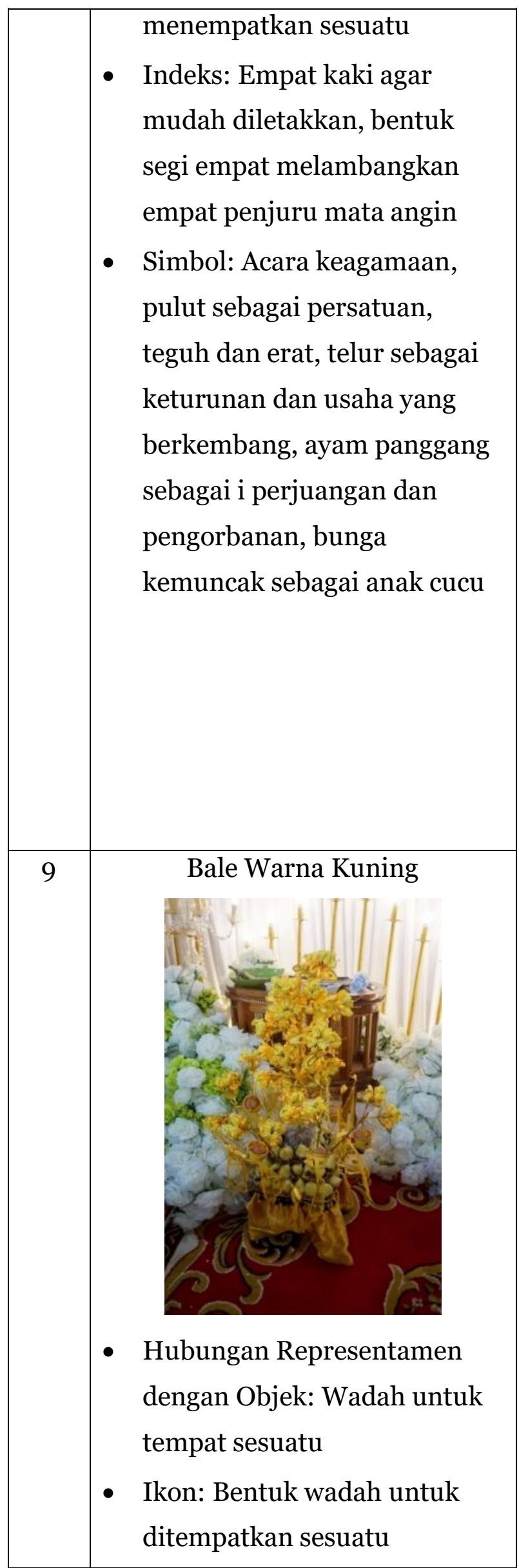

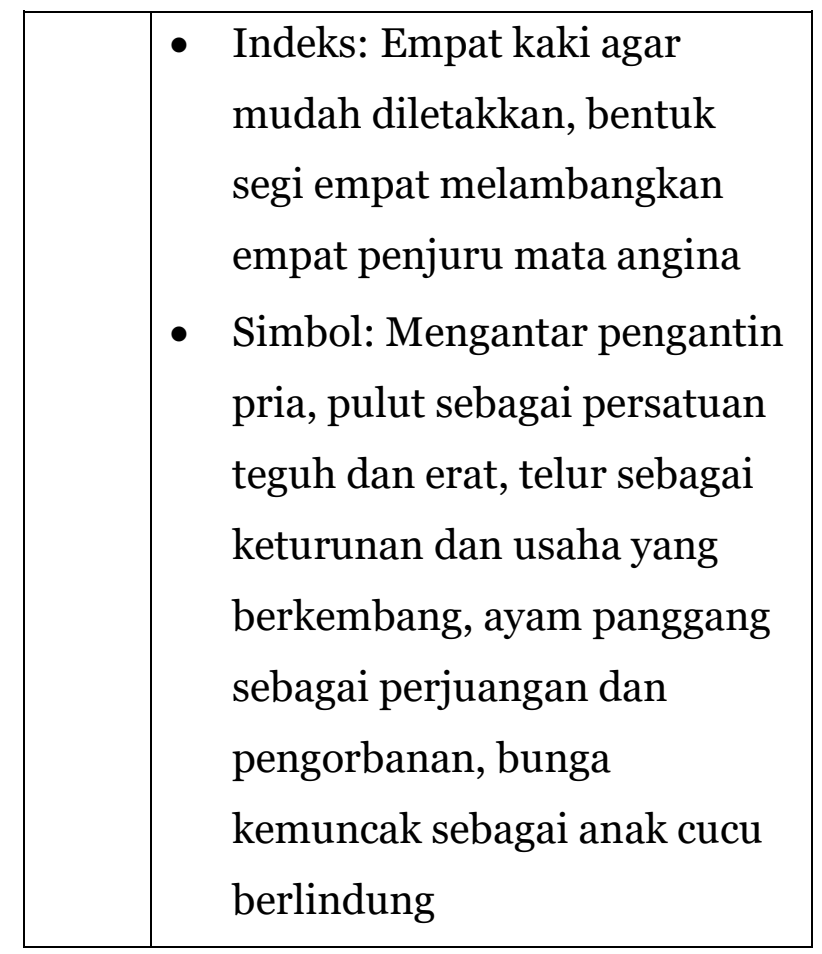

\section{Tabel Hasil Identifikasi Objek Penelitian Berdasarkan Aspek Interpretan}

\begin{tabular}{|c|c|}
\hline No. & \multicolumn{2}{|c|}{ Gambar } \\
\hline 1 & Tepak Sirih Berwarna Coklat \\
$\bullet$ & Interpretan: Adat/budaya \\
& Melayu \\
$\bullet$ & Rema: Adat/budaya Melayu \\
& Disen: Digunakan untuk \\
tempat sirih \\
Argumen: Tempat yang \\
digunakan untuk menyajikan
\end{tabular}




\begin{tabular}{|c|c|}
\hline & $\begin{array}{l}\text { sirih beserta perencahnya } \\
\text { sebagai sarana pembuka kata }\end{array}$ \\
\hline 2 & $\begin{array}{l}\text { - Interpretan: Adat/budaya } \\
\text { Melayu } \\
\text { - } \text { Rema: Adat/budaya Melayu } \\
\text { Disen: Digunakan untuk } \\
\text { tempat sirih } \\
\text { Argumen: Tempat yang } \\
\text { digunakan untuk menyajikan } \\
\text { sirih beserta perencahnya } \\
\text { sebagai sarana pembuka kata }\end{array}$ \\
\hline 3 & $\begin{array}{l}\text { Sirih Sebagai Isi Tepak Sirih } \\
\text { - } \quad \text { Interpretan: penghormatan } \\
\text { Rema: Makan sirih, isi tepak } \\
\text { sirih } \\
\text { Disen: Sirih merupakan } \\
\text { tanaman menjalar } \\
\text { Argumen: Sirih merupakan } \\
\text { tanaman menjalar } \\
\text { melambangkan sifat } \\
\text { merendah diri dan senantiasa } \\
\text { memuliakan orang lain }\end{array}$ \\
\hline
\end{tabular}

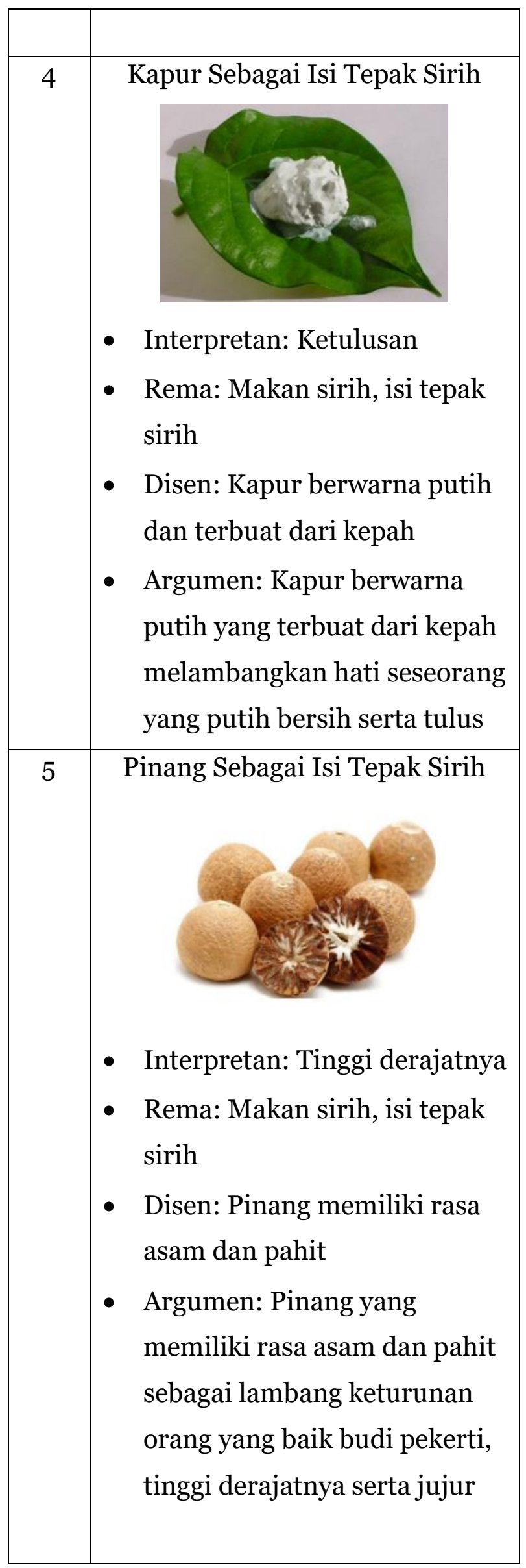




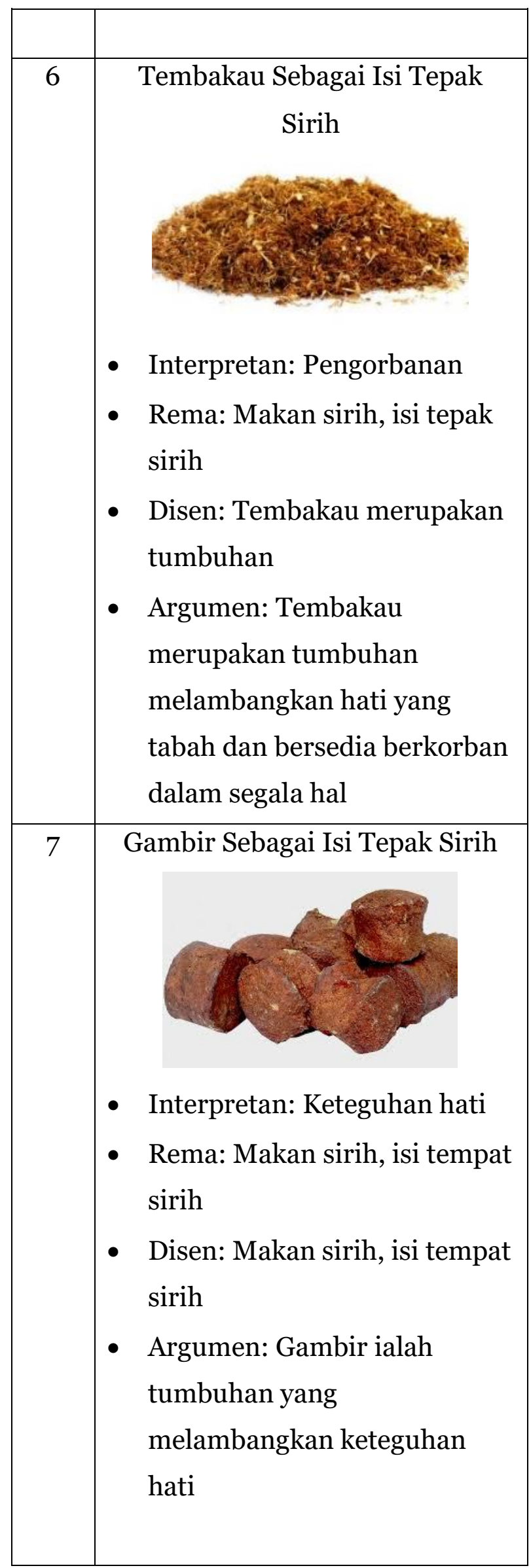

\begin{tabular}{|c|c|}
\hline 8 & $\begin{array}{l}\text { - Interpretan: Adat/budaya } \\
\text { Melayu } \\
\text { mema: Khitanan, melepas dan } \\
\text { khatam al-quran } \\
\text { Disen: Bale Melayu } \\
\text { merupakan tempat telur dan } \\
\text { pulut bertingkat tiga } \\
\text { Argumen: Bale Melayu } \\
\text { merupakan tempat pulut dan } \\
\text { telur yang terdapat pada saat } \\
\text { acara khitanan, melepas dan } \\
\text { menyambut jamaah haji, dan } \\
\text { khatam al-quran }\end{array}$ \\
\hline 9 & $\begin{array}{l}\text { Interpretan: Adat/budaya } \\
\text { Melayu }\end{array}$ \\
\hline
\end{tabular}


- Rema: Pesta pernikahan

- Disen: Bale merupakan tempat telur dan pulut bertingkat tiga

- Argumen: Bale Melayu merupakan tempat pulut dan telur yang dibawa saat mengantarkan pengantin pria ketempat pesta pernikahan

Hasil penelitian di atas merupapan paparan representamen, hubungan representamen dengan objek dan interpretan secara umun dari masingmasing tepak sirih dan bale Melayu di Kecamatan Medan Deli. Paparan data tersebut muncul saat memperhatikan tepak sirih dan bale Melayu secara keseluruhan.

\section{PENUTUP}

Setiap objek visual yang terdapat pada tepak sirih dan bale Melayu memiliki relasi tanda dan makna tersendiri, yang dapat memunculkan persepsi berbeda- beda. Persepsi atau pemahaman ini lahir adalah berdasarkan kenyataan tekstual,didukung kondisi dan situasi kontekstual, serta persepsi pengamat. Hasil dari penelitian ini menunjukkan tepak sirih dan bale Melayu di Kecamatan Medan Deli mengandung makna aspek reprsesentamen, hubungan representamen dengan objek dan interpretan.

\section{DAFTAR PUSTAKA}

Budiman, K. (2011). Semiotika visual: konsep, isu, dan problem ikonisitas. Jalasutra.

Mubarat, H. (2016). Kajian Bentuk dan Fungsi Seni Kerajinan Lakuer Tepak Sirih Palembang. Besaung: Jurnal Seni Desain Dan Budaya, 1(1).

Patriansyah, M. (2014). Analisis Semiotika Charles Sanders Peirce Karya Patung Rajudin Berjudul Manyeso Diri. Ekspresi Seni: Jurnal Ilmu Pengetahuan Dan Karya Seni, 16(2), 239-252.

Ramadhan, A. Z. (n.d.). ANALISIS SEMIOTIKA IKLAN CETAK LA LIGHTS "JANGAN MAU DIADU" VERSI AYAM. Gorga: Jurnal Seni Rupa, 9(2), 232-235.

Salleh, N. (2014). Tepak Sirih: Interpretasi dan Persepsi dalam Masyarakat MalaysiaIndonesia. Jurnal Komunikasi Borneo (JKoB).

Sobur. (2004). Kemiotika Komunikasi. PT Remaja Rosdakarya.

Sudiani, Y. (2016). Analisis Desain Uang Kertas Pecahan Seratus Ribu Rupiah. Ekspresi Seni: Jurnal Ilmu Pengetahuan Dan Karya Seni, 18(2), 324-332.

Sugiyono. (2017). Metode Penelitian Kualitatif, Kuantitatif, dan $R \& B$. alfabeta.

Yusuf. (2014). Metode Penelitian: Kuantitatif, Kualitatif, \& Penelitian Gabungan.

Zulkifli, Z., Atmojo, W. T., Kartono, G., \& Nurwani, N. (2021). Revitalisasi Identitas Melayu: Studi Penerapan Ragam Hias Tradisonal Melayu pada Bangunan Modern di Kota Medan. Journal of Education, Humaniora and Social Sciences (JEHSS), 3(3), 895-903. 
